\title{
Rectification of Turbo lags in Turbocharger
}

\author{
Palani S, Sathiyamoorthy V, Balamurugan S, Sivakumar A, Arumugam K
}

\begin{abstract}
A turbocharger is the most used component in an automobile. It is widely employing in marine engines and aircraft engines to provide dense air to the combustion chamber. Due to the friction between the bearings and the own impeller weight of the rotors of the turbine and compressor turbo lag is caused. To rectify the turbo lag, we proposed magnetic Levitation principle. The use of magnets can reduce friction to a great extent, further it increases the efficiency of the turbocharger. The implementation magnetic levitation concept in the conventional turbocharger reduces the friction to a greater extent and decreases the turbo lag since the shaft of the turbocharger levitates freely and so less power is required to drive the shaft. The bearings are replaced by levitation concept hence there is no requirement for lubrication of bearings thus reducing the weight, space occupied, and making the turbocharger more efficient than the present one.
\end{abstract}

Keywords: Combustion chamber, Magnetic levitation, Turbocharger, Turbo lag.

\section{INTRODUCTION}

$\mathrm{T}$ urbocharger is a device that uses potential energy of the exhaust gases to rotate the turbine which in turns rotates the compressor as they are attached to same shaft. Due to rotation of the compressor wheel there occurs a pressure drop eventually leading to suction of atmospheric gases in the chamber of combustion. Air-fuel mixture generates additional power furthermore it burn fuel high efficiently and allow improving performance of the engine.

Nowadays most of the automobiles are turbocharged due to the likeness in increase in efficiency and power for less fuel consumption. Consider a turbocharger with no defects just running in perfect condition with no friction and the power manipulated by it. It will be a benchmark in the automobile technology as there will be no defects in turbocharger by using the concept of magnetic levitation in

Revised Manuscript Received on December 30, 2019.

* Correspondence Author Avadi, Chennai-600 062, India. Email: spalani@veltechmultitech.org

Sathiyamoorthy V*, Department of Mechanical Engineering, Vel Tech High Tech Dr. Rangarajan Dr. Sakunthala Engineering college, Avadi -600 062, Tamil Nadu, India. Email: drvsathiyamoorthy@gmail.com

Balamurugan S, Department of Mechanical Engineering, Mahendra College of Engineering, Salem, Tamil Nadu, India. Email: sbalmu@yahoo.com

Sivakumar A, Department of Mechanical Engineering, Varuvan Vadivelan Institute of Technology, Dharmapuri-636 703, Tamil Nadu, India. Email: sirarira@gmail.com

Arumugam K, Principal, Gojan School of Business and Technology, Redhills, Chennai -600 052, Chennai, Tamil Nadu, India. Email: aru963dr@gmail.com

(C) The Authors. Published by Blue Eyes Intelligence Engineering and Sciences Publication (BEIESP). This is an open access article under the CC BY-NC-ND license (http://creativecommons.org/licenses/by-nc-nd/4.0/)
Palani S*, Department of Mechanical Engineering, Vel Tech Multitech,

this field. Four magnets placed $120^{\circ}$ each other produces enough magnetic flux lines to levitate the shaft which rotates freely like a floating shaft not demanding much energy for the rotation of the shaft, hence low power Is required to drive the rotors located on the shaft at equal distances from the centre of the shaft. Turbo lag as consider as the most serious problem because the initial mass production started. A number of novel technologies like geometry of turbo charger variable, ceramic turbocharger were introduced for improving performance of the acceleration. The different geometrical turbocharger changing the gas flow area passage as well as improving the speed of the exhaust gas at low engine speeds.

Adaptive control system is the copes by means of the structural alterations constraints with the system for magnetic levitation was recommended [1] [7]. The minimum cost application of controllers viewed in connection by complication of regulator algorithms [2] [9] [10].The classical as well as adaptive regulator construction has proposed to place the control system and their applications of the system of magnetic levitation [3].

The methodical excellent of PID-GS-C constraint is stand for the way of upcoming research through ensuring best tuning by means of classical investigation through guarantee ideal tuning by conventional as well as recent optimization algorithms [4] [11]. Another stimulating adaptive advance setting up control methods with actual realistic functions were agreed [5] [8]. The process parameters found numerically and experimentally [6].

A state feedback control structure (SFCS) initially planned with the intention of system stabilize throughput on signal for control at the higher electro magnet [12]. The virtual outside trouble could be useful for bottom electro magnet. Initial SFCS was the subsequent restricted through a Proportional Integral Derivative Gain Scheduling Control (PIDGSC) structure [9] [13].The design methods has the classical PIDGSC) system positioning [14, 15, 16].

Turbochargers are widely used as a boosting component in automobile engines where it boosts the engine power and $\mathrm{rpm}$. But turbo lag is considered as the major drawback in the performance of the turbocharger.

In our research work magnetic levitation principle is brought into effect. This principle uses the repelling forces of the surrounding magnets to levitate the shaft of the rotors thus decreasing the friction caused by the bearings and this also reduces the surging which is caused in turbocharger when there is a change in the performance of the engine.

\section{TURBOCHARGER}

The function of a turbocharger is to induce forced air into the combustion chamber in order to increase the engine's efficiency and power output.

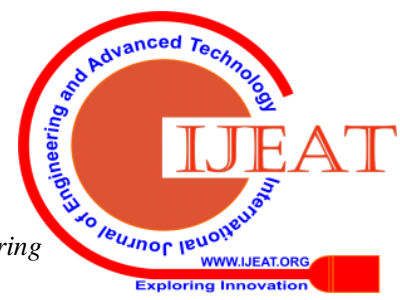




\section{Rectification of Turbo lags in Turbocharger}

Earlier days they are mainly used in aviation industries to force the air into the combustion chamber of the jet or airplane, now they are widely used in automobile sectors to boost the power output. This is possible because of the highly dense cool air is induced into the combustion chamber by the turbine driven compressor.

In the developing stages they were called as superchargers. Then later on development, supercharger refers to the device that uses a compressor which is belt driven by flywheel is employed in forcing the ambient air into the combustion chamber. This uses power from the flywheel to drive the compressor resulting in induction of ambient air into the combustion chamber. This is less efficient than the turbocharger which does not require any power from the engine auxiliaries and the engine itself except the exhaust gases from the engine.

Turbochargers can be used in any type of engines like marine vessels, heavy vehicles, compact vehicles, race vehicles to increase the power output at the same time to provide eco-friendly solutions.

By way of the global trend for protecting the atmosphere, the legislation of emissions is improving in stringent. Functions of the vehicles are individually analyzed from preserving point in the world atmosphere. It is also for developing cars with environmental responsive. The cars are need high console as well as enhanced drivability compare with still before to meet these necessities. Recently, the purpose of turbocharged diesel engines has been improved. Variable geometry turbocharger i.e. called VGT like VNT is receiving more awareness in the automobile industries and important advantage and creature for enhancing the torque of the engine and the region of minimum speed without the performance compromise on the region of high speed.

The applications of turbochargers can be classified according to the power requirements of the vehicles and according to the drive surface. Some vehicles need large rotors to induce sufficient air into the chamber, race vehicles employ small turbo to meet the power criteria. Marine vessels need medium sized turbochargers to meet the demand produced by the engine. So the turbochargers are selected based on power requirement of the engine used.

\section{A. Turbo Lag}

Turbo lag also known as turbocharger lag is the main and important drawback of using the turbochargers. Many new developments were made to reduce the drawback. Turbo lag is the time taken for the exhaust gas to rotate the turbine, the time lag for actual boosting starts is known as turbo lag. In general it is the time required for the boosting with respect the required throttle change.

\section{B. Surging in Turbocharger}

Surging in turbocharger occurs when the pressure of air present in the inlet manifold is greater than the pressure that the compressor housing can maintain. This happens when the pressure delivered by the compressor to the combustion chamber is greater than pressure inside the compressor. This eventually leads to the backflow of the compressor or restriction of the compressor movement, thereby reducing the efficiency of the device and affecting the engine performance. Surging produces sudden decrease in flow and the speed of air due to restricted movement of air and back pressure created. This could cause heavy damage to the turbocharger. Rapid change in load, Insufficient supply of fuel, Fault in fuel systems, Restriction of scavenge process, Narrowed exhaust gas passages, Engine operation at overload failure of turbine blade, nozzle/diffuser.

\section{MAGNETIC LEVITATION}

Magnetic levitation or magnetic suspension is the technique which employs magnets placed at a certain order to create a magnetic field, when a magnet is placed in this field it makes the magnet to levitate i.e., float. This is due to the presence of strong magnetic force created by the surrounding magnets. The magnets place at an angle produces a sufficient lift force so that it lifts the magnet placed in between them.

\section{A. Magnetic levitation in Conventional Turbocharger}

The concept is simple but very effective, and is used in many applications but it is the first time to be used in a conventional turbocharger where it can effectively reduces the above mentioned problems and also can be used in the places where it can be replaced by the conventional bearings. When the pressure of the intake air increases it leads to more power output from the engine, the general boost pressure created is 33bar to 1 bar. The ideal burning conditions of an engine is $14.7: 1$, so when you burn more air eventually you have to burn more fuel..These conditions are generally used at higher altitudes where the engine finds difficult to force the air into the combustion chamber. Also plays a role in increasing the density of air, denser the air more amount of oxygen is present.

\section{B. Remedy for this situation}

The Prototype without housings is shown in Figure 1.

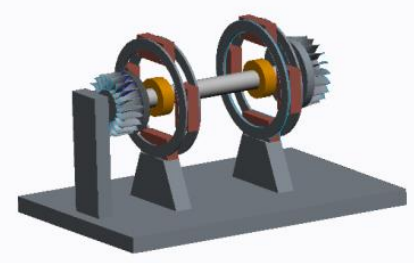

Figure 1: Prototype without housings

A magnetically levitated shaft can be used in the place conventional shaft which rotates freely without any friction so there by drawing the ambient air from the atmosphere and forcing it into the combustion chamber so that the power at the higher altitudes is same as that of the sea level. Figure 2 shows the prototype point contact.

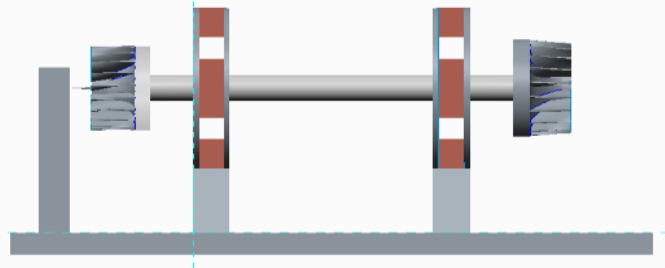

Figure 2 Prototype showing point contact

\section{Material Selection}

The casing is the part that surrounds the turbine and compressor wheel.
Blue Eyes Intelligence Engineering \& Sciences Publication 
The desirable property is light weight, harder and temperature withstanding material up to $850-1050^{\circ} \mathrm{C}$. Strength and stiffness are the two most important characteristics of the housing and by using lighter weight materials. As it has a complex shape it is tedious process to manufacture the part. Cast- machining process is undergone for the manufacture of the product. It should have high service life and high temperature withstanding property. The material with the above mentioned properties is too expensive.

\section{Suitable Material for Casing}

Chromium nickel alloy, A-286, solution treated and aged / simo cast Iron, grey iron. The percentage of elongation and tensile strength of chromium are shown in Figure 3.

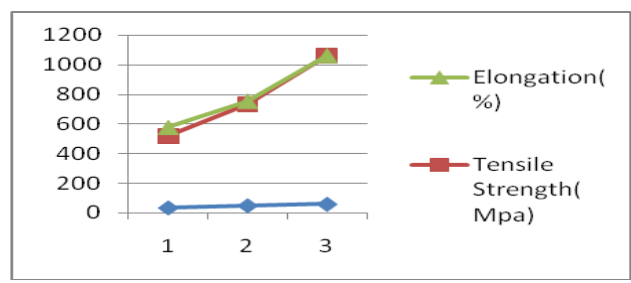

Figure 3: Percentage of elongation and tensile strength of chromium

\section{E. Impeller and Turbine}

The impeller and turbine materials should have high temperature withstanding capacity as the exhaust gas temperatures may reach up to $200-600^{\circ} \mathrm{C}$. Also lighter materials have to be chosen for effective rotation of the rotors and bulkier materials are difficult to rotate. Suitable Material for impeller is Aluminum alloy C355. The Suitable Material for turbine is Ni-base alloys. The prototype with housings designed using CAD is shown in Figure 4.

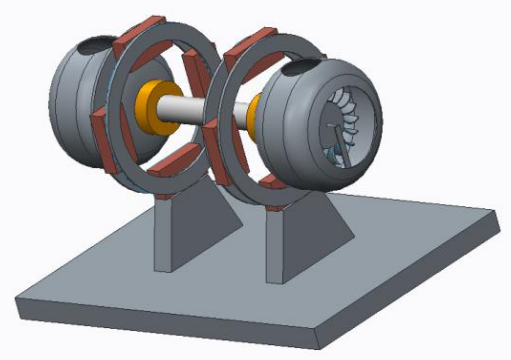

Figure 4: prototype with housings designed using CAD

\section{CALCULATIONS}

\section{A. Force between Two Magnets}

The magnetic force between two bar magnets identical in shape is approximately given by the following relation:

$$
F=\left[\frac{B_{0}^{2} A^{2}\left(L^{2}+R^{2}\right)}{\pi \mu_{0} L^{2}}\right]\left[\frac{1}{x^{2}}+\frac{1}{(x+2 L)^{2}}-\frac{2}{(x+L)^{2}}\right]
$$

Where

$B_{0}$, It represents the flux density in $\mathrm{T}$

$A$, It represents the pole area in $\mathrm{M}^{2}$

$L$, this indicates the length of the magnet in $\mathrm{M}$

$R$, It represents the radius of an individual magnet in $\mathrm{M}$

$X$, it represents the separation distance in $\mathrm{M}$

$$
\mathrm{B}_{0}=\mu_{0} \mathrm{M} / 2
$$

$M$ represents the magnetization in $\mathrm{A} / \mathrm{M}$,

$\mu_{0}$, indicates the magnetic permeability of vacuum, is $4 \mathrm{pi} \times 10^{-7} \mathrm{~N} / \mathrm{Amp}^{2}$

Where, $\mathrm{M}=\mathrm{B}_{\mathrm{r}} / \mu_{0}$

$B_{\mathrm{r}}$ represents remenance for grade $\mathrm{N}_{35}=1.17$ Tesla

$\mathrm{M}=(1.17) /\left(4 \pi^{*} 10^{-7}\right)$

$\mathrm{B}_{0}=\left(2 \pi^{*} 10^{-7}\right) * 9.31 * 10^{5}$

$\mathrm{B}_{0}=0.585 \mathrm{~T}$

$A=3.772 * 10^{-3}$

$L=2.3 * 10^{-2}$

$R=0.02$

$x=0.01$

$\mathrm{F}=\left\{0.585^{2}\left(3.77 * 10^{-3}\right)^{2}\left[\left(2.3 * 10^{-2}\right)^{2}+(0.02)^{2}\right]\right\}$

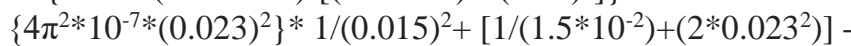

$\left[2 /(0.015+0.023)^{2}\right]$

$\mathrm{F}=41799.59 * 16798685.9$

$\mathrm{F}=7.02 \times 10^{-2}$

\section{B. Magnetic dipole moment}

The dipole moment of a magnet is a property that measures the torque by it in an external magnetic field. A molecule, an electron, a magnet are some of the examples which have dipole moment. The dipole moment is assumed to be a vector quantity which ahs both magnitude and direction. The dipole moment direction ranges from South Pole to North Pole of a magnet.

$\mathrm{m}=\mathrm{B}_{\mathrm{r}} * \mathrm{~V} / \mu_{0}$

$\mathrm{V}=\mathrm{l} * \mathrm{~b} * \mathrm{~h}$

$\mathrm{m}=\left(1.17 * 1.2696 * 10^{-5}\right) /\left(4 \pi^{*} 10^{-7}\right)$

\section{$\mathbf{M}=11.82$ AM $^{2}$}

\section{Magnetic induction}

Genetic induction can be defined as the magnetic field produced by a field strength $\mathrm{H}$ in a given point. The unit area normal to the magnetic field direction is known as magnetic induction.

$\mathrm{B}=\mathrm{B}_{\mathrm{r}} / \pi\left[\left(\mathrm{L}^{*} \mathrm{~W}\right) /\left(2 \mathrm{Z} \sqrt{ }\left(4 \mathrm{Z}^{2}+\mathrm{L}^{2}+\mathrm{W}^{2}\right)\right)\right]$

$\mathrm{B}=1.17 / \pi\left[(0.023 * 0.046) /\left(0.02 \sqrt{ }\left(4 * 0.01^{2}+0.023^{2}+0.046^{2}\right)\right)\right]$

$\mathrm{B}=71.42 \mathrm{~T}$

\section{Magnetic field strength $(\mathbf{H})$}

Genetic field strength is the measure of the magnetic quantity that helps in determination of the ability of the electric current or a magnetic body to produce a magnetic field at a given point, it is measured in oversteps

$\mathrm{H}=\left[\mathrm{B} / \mu_{0}\right]-\mathrm{M}$

$\mathrm{H}=\left[71.40 /\left(4 \pi^{*} 10^{-7}\right)\right]-9.31 * 10^{5}$

$\mathrm{H}=55.89 * 10^{6}$ Oersteds

\section{Verification}

Wkt

$\mathrm{B}=\mu_{0} *(\mathrm{M}+\mathrm{H})$

$\mathrm{B}=\left(4 \pi^{*} 10^{-7}\right) *\left(9.31 * 10^{5}+55.89 * 10^{6}\right)$

$\mathrm{B}=\mathbf{7 1 . 4 0} \mathrm{T}$

Therefore the magnetic strength satisfies the above equation.

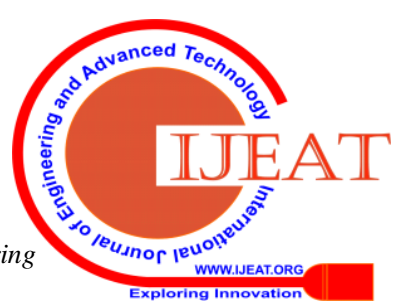




\section{Rectification of Turbo lags in Turbocharger}

\section{E. Magnetic flux}

This term is derived when attempted to explain the flow of magnetic field. Magnetic induction is derived when the induction $\mathrm{b}$ is distributed over a uniform area A normally,

$$
\begin{aligned}
& \varnothing=\text { BA. } \\
& \varnothing=71.40 * 3.772 * 10^{-3} \\
& \varnothing=\mathbf{0 . 2 7} \text { wb }
\end{aligned}
$$

Therefore the value of flux satisfies the above equation.

\section{RESULTS AND DISCUSSIONS}

It is to be noted that when speed of the shaft increases the shaft rotates stably even at high rpm like 1500, 2000, etc. This is achieved due to the usage of strong magnets called neodymium magnets which helps the shaft to rotate in constant stability, due to its strong magnetic field. This test was conducted using single stage reciprocating air compressor, tachometer. The results of the experiments conducted are tabulated in Table 1.

Table 1 Experimental results for Speed vs Stability

\begin{tabular}{|c|c|c|l|}
\hline S. no. & Speed(rpm) & Pressure(bar) & Stability \\
\hline 1 & 1320 & 1 & Stable \\
\hline 2 & 1275 & 2 & Stable \\
\hline 3 & 1243 & 3 & Stable \\
\hline 4 & 1160 & 4 & Stable \\
\hline
\end{tabular}

The loss of magnetic property at particular temperature is called as Curie temperature. For neodymium magnets the Curie temperature is around $900-1000^{\circ} \mathrm{c}$. So there is no chance to reach such temperature as the neodymium magnets are placed outside the rotor housings and is completely surrounded by non conducting materials. The experiments are conducted and the results were appreciable by placing a magnet in an electronically flame, and the results are given below in the form of Table.

As the distance between two magnets increases the repulsive or attractive force between them gets ineffective because distance is inversely proportional to the magnetic property. The effect of magnetic field strength and distance is shown in Figure 5.

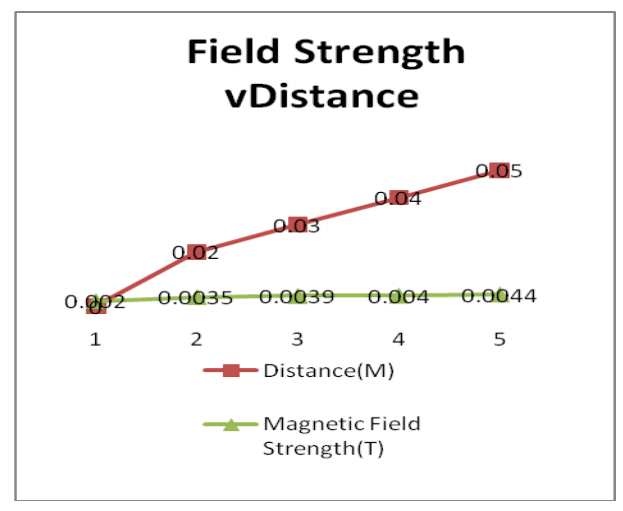

\section{Figure 5: Effect of magnetic field strength and distance}

In this prototype distance between ring and bar magnets played a major role in the levitation of the shaft. Also the bars magnets also have to be placed at an angle of $120^{\circ}$ to each other to effectively levitate the shaft which is responsible for the stability of shaft.

\section{CONCLUSION}

Instead of using a conventional turbocharger, a magnetically levitated turbocharger occupies less space, reduces complexity, maintenance. The cons of the turbocharger can be avoided when using this concept in the existing one. When the speed of the shaft increases, more the intake charge it supplies to the combustion chamber and thus the engine produces more power when compared to the conventional one, and also turbo lag can be reduced as the shaft rotates freely. This project is still in its developing stage as the impellers of the turbine and compressor rotors have to be designed in such a way that the leakage of air from the housings has to be reduced completely or to a minimal level. Surging of turbochargers can also be neglected when Magnetic levitation is used as the speed of the shaft is high and the shaft can rotate freely for several minute at the same speed without decelerating thus it is impossible for surging to affect the performance of these kinds of turbochargers. In addition this concept can also be used for power generation.

\section{REFERENCES}

1. An S, Ma Y and Cao Z (2009), "Applying simple adaptive control to magnetic levitation system", Proceedings of 2nd International Conference on Intelligent Computation Technology and Automation, Changsha, Hunan, China, 1, 746-749, 2009

2. Colhon M and Danciulescu D (2010), "emantic schemas for natural language generation inmultilingual systems", Journal of Knowledge Communications and Computing Technologies,2(1), 10-17, 2010

3. Bianchi FD and Sánchez Peña RS(2011), "Interpolation for gain-scheduled control with guarantees", Automatica, 47(1), 239-243, 2011

4. Angelov P and Yager R (2012), “A new type of simplified fuzzy rule-based systems" International Journal of General Systems, 41(2), 163-185, 2012

5. Bianchi FD, Sánchez Pena RS, and Guadayol M (2012), "Gain scheduled control based on high fidelity local wind turbine models", Renewable Energy, 37(1), 233-240, 2012

6. Dragos CA, Precup RE, David RC, Preitl S, Stinean AI and Petriu EM (2013), "Simulated annealing based optimization of fuzzy models for magnetic levitation systems", Proceedings of 2013 Joint IFSA World Congress and NAFIPS Annual Meeting, Edmonton,AB, Canada, 286-29, 2013

7. Chauhan S and Nigam MJ (2014), "Model predictive controller design and perturbation study for magnetic levitation system", Proceedings of 2014 IEEE Recent Advances in Engineering and Computational Sciences, Chandigarh, India, 1-6, 2014

8. Bedoud K, Alirachedi M, Bahid T and Lakel R (2015), “ Adaptive fuzzy gain scheduling of PI controller for control of the wind energy conversion systems", Energy Procedia, 74, 211-225,2015

9. Danciulescu D (2015), "Formal languages generation in systems of knowledge representation based on stratified graphs", Informatica, 26(3), 407-417, 2015

10. Derr KW and Manic M (2015), "Wireless sensor networks node localization for various industry problems", IEEE Transactions on Industrial Informatics, 11(3), 752-762, 2015

11. Deliparaschos K, Michail K, Zolotas A and Tzafestas S (2016), "FPGA-based efficient hardware/software co-design for industrial systems with systematic sensor selection", Journal of Electrical Engineering, 67(3), 150-159, 2016

12. Bojan Dragos CA, Preitl S, Precup RE, Hergane S, Hughiet EG and Szedlak Stinean AI (2016), "State feedback and proportional-integral-derivative control of a magnetic levitation system", Proceedings of IEEE 14th International Symposium on Intelligent Systems and Informatics, Subotica, Serbia, 111-116, 2016 
13. Bojan Dragos CA, Preitl S, Precup R.E, Hergane S, Hughiet EG and Szedlak Stinean AI (2016), "Proportional integral gains scheduling control of a magnetic levitation system", Proceedings of 20th International Conference on System Theory, Control and Computing, Sinaia, Romania, 1-6, 2016

14. Bojan Dragos C A, Precup R E, Tomescu M L, Preitl S, Tanasoiu O M and Hergane S, "Proportional Integral Derivative Gain Scheduling Control of a Magnetic Levitation System", International Journal of Computers Communications \&Control",12(5), 599-611, October 2017.

15. Sathiyamoorthi, V and Sekar, T 2016, „Optimization of Processing Parameters in ECM of Aisi 202 Using Multi Objective Genetic Algorithm"', The International Journal of Enterprise Network Management, Vol. 7, No. 2, pp.133-141.

16. Sekar T, Arularasu M and Sathiyamoorthi V, 2016, Investigations on the effects of Nano-fluid in ECM of die steel"e, Measurement, Elsevier, Volume 83, pp. 38-43

\section{AUTHORS PROFILE}

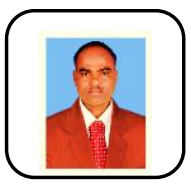

Palani S was born in Madurai, Tamilnadu, India, in 1967. He received the B.E., degree in Mechanical Engineering from M.K. University, Madurai, Tamilnadu, India in 2003, and the M.E., and Ph.D. degrees in Manufacturing Engineering from the Anna University, Chennai, Tamilnadu, India in 2005 and 2013, respectively. He has 13 years of experience in teaching and research and working as an Associate Professor in the Department of Mechanical Engineering, Vel Tech Multitech Dr. Rangarajan Dr. Sakunthala Engineering College, Avadi, Chennai-600 062. His research area include Advanced Manufacturing Technology, Artificial Intelligent Techniques, Machine Vision, On-line Monitoring, Material Science, Bio-Fuel, Heat Exchanger etc., He published more than 100 research papers through National and International Journals and Conferences. He is an authorized Research Supervisor for Anna University and Guiding more than 7 Ph.D., research scholars. He was awarded as a "Distinguished Scientist" by Venus International Foundation -Research Awards-VIRA 2016. He is a Life member of MISTE [LM91981] in professional bodies.

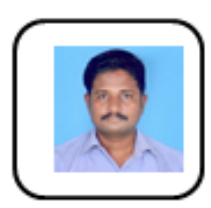

Sathiyamoorthy V born in 10th May 1983 at Salem, Tamil Nadu, India. He has obtained his Unde Graduate Degree (B.E) in Mechanical Engineering, from Anna University, Chennai in the year 2006. He obtained his Post Graduate Degree in Master of Engineering with a specialization in Computer Aided Design from Anna University, Chennai in the yea 2006. He obtained his Ph.D. Degree from Anna University, Chennai in the year 2015. His areas of interest are Advanced machining, Optimization, Nano materials, Nano fluid, Design of experiments, Material Science, Artificial Intelligence, Machine learning, etc. Currently he is working as Associate Professor of Mechanical Engineering Department, Vel Tech High Tech Dr. Rangarajan Dr. Sakunthala Engineering college, Avadi -600 062, Tamil Nadu, India. He is having twelve years of teaching experience in Engineering Colleges. He has published more than sixty one papers in International and National Journals and conferences. He has authored three text books in the field of advanced manufacturing for the betterment of young researchers. He is a recognized research supervisor of Anna University, Chennai and Life member of Institution of Engineers India (IEI), Indian Society for Technical Education (ISTE).

Balamurugan S born in 10th April 1972 at Salem,

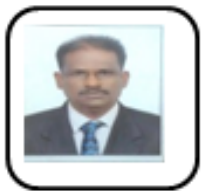

Tamil Nadu, India He has obtained his Unde Graduate Degree (B.E) in Mechanical Engineering, from Madras University, Chennai in the year 1993. He obtained his Post Graduate Degree in Master of Engineering with a specialization in Computer Aided Design from Anna University, Chennai in the year 2004. He obtained his Ph.D. Degree from Anna University, Chennai in the year 2013. His areas of interest are Vibration, Optimization, Advanced Manufacturing Technology, Material Science, Artificial Intelligence, Machine learning, etc. Currently he is working as Professor and Head of Mechanical Engineering Department, Mahendra College of Engineering, Salem, Tamil Nadu. He is having twenty years of teaching experience in Engineering Colleges and five years Industry experience. He has published twenty three papers in International and National Journals and conferences. He has authored two text books for the Engineering Students. He is a recognized research supervisor of Anna University, Chennai and Life member of Institution of Engineers India (IEI), Indian Society for Technical Education (ISTE)

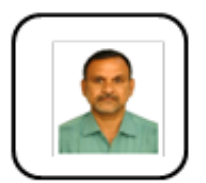

Sivakumar A was born in Salem, Tamil Nadu, India. He obtained his U.G Degree in Mechanical Engineering Discipline from University of Madras during 1995, followed by his M.E in Thermal Engineering in 2004, from Annamalai University, Tamil Nadu, India. Apart from these, he has an M.S. degree in Education Management, Post Graduate Diploma in Business Administration, and Diploma in Maintenance Engineering. He was awarded with Doctoral Degree by Anna University, Chennai, Tamil Nadu. Regarding his experience, he has an 18 year unblemished service in academic field, 5 years industrial exposure. He has authored three text books in the field of advanced manufacturing for the betterment of young researchers. Presently working as a professor in the Department of Mechanical Engineering, Varuvan Vadivelan Institute of Technology, Dharmapuri-636 703, Tamil Nadu. He is a life member in various professional bodies.

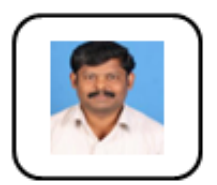

Arumugam K is presently working as a Principal in Gojan School of Business and Technology, Chennai. He has obtained his B.E. (Mechanical Engineering) degree from University of Madras and M.E. (Thermal Power Engineering) from Annamalai University. Also he awarded Ph.D. (Mechanical Engineering) from Anna University. He has more than 20 Years of working experience in teaching. To his credit he also published more than 45 Research Papers in various International and National Journals and Conferences. He is also a life member of various professional bodies including Indian Society for Technical Education (ISTE) and Fellow Member in International Society for Research and Development. He has filed three patents in IPR 